\title{
Flail Chest Associated with a Simple Fall and Successful External Tamponade Application in a Pediatric Case
}

\author{
Ismail Altintop ${ }^{*}$, Nurcan Gunarli1, Mithat Fazlioglu ${ }^{2}$ \\ ${ }^{1}$ Department of Emergency Medicine, Kayseri Training and Research Hospital, Kayseri, Turkey \\ ${ }^{2}$ Department of Thoracic Surgery, Kayseri Training and Research Hospital, Kayseri, Turkey \\ Email: ${ }^{*}$ draltintop1@hotmail.com
}

Received 4 November 2014; revised 3 December 2014; accepted 16 December 2014

Academic Editor: Pablo Sanz Ruiz, Gregorio Marañón General Hospital, Spain

Copyright (C) 2014 by authors and Scientific Research Publishing Inc.

This work is licensed under the Creative Commons Attribution International License (CC BY).

http://creativecommons.org/licenses/by/4.0/

(c) (i) Open Access

\begin{abstract}
A flail chest is characterized by four or more rib fractures unilaterally or at more than two sites. The current article reports a 10-year-old case of a flail chest due to a simple fall from a chair while at breakfast. This pediatric case is presented because of its rare occurrence with a successful external tamponade application. Pneumothorax and tension pneumothorax associated with simple falls should be considered in pediatric patients. In the current case, blunt chest trauma-associated bilateral multiple rib fractures and a flail chest were present. The chest wall was destabilized and respiratory functions were compromised. Early stabilization with tube thoracostomy and external tamponade were achieved in the emergency setting. Intubation was not required after these procedures.
\end{abstract}

\section{Keywords}

\section{Flail Chest, Pneumothorax, External Tamponade}

\section{Introduction}

A flail chest is clinically diagnosed as paradoxical respiration or movement of a segment of the chest wall [1]. The clinical presentation includes severe pain, dyspnea, and mechanical dysfunction of the lungs [1] [2]. Mechanical ventilation is often required. The mortality and morbidity rates are higher in adults than pediatric patients. Children usually respond to treatment very well. Early intervention is crucial in the management of a flail chest. In

\footnotetext{
${ }^{*}$ Corresponding author.
}

How to cite this paper: Altintop, I., Gunarli, N. and Fazlioglu, M. (2014) Flail Chest Associated with a Simple Fall and Successful External Tamponade Application in a Pediatric Case. Case Reports in Clinical Medicine, 3, 660-663. 
most cases, there should be no delay in radiographs to confirm the diagnosis [2] [3]. Surgical fixation is performed in lieu of conservative treatment modalities in severe trauma injuries.

\section{Case Progression}

A 10-year-old boy was admitted to the trauma unit of the emergency department with dyspnea. The patient history revealed that he fell from the chair to the ceramic-tile ground while having breakfast. He was brought to the emergency department (ED) by his family due to a sudden onset of dyspnea. His family reported that the time to ED visit was nearly 10 minutes. The patient presented with an oxygen saturation of $80 \%$ with severe dyspnea and tachypnea $(32 \mathrm{bpm})$. Physical examination revealed that a paradoxical respiratory movement indicating flail chest in a $8 \times 10$-cm zone at the level of sixth and ninth ribs of the posterior axillary line of the left chest wall, accompanied by subcutaneous emphysema and ecchymosis. Inflation and deflation movements were observed during respiration. The patient who presented with dyspnea as well as tachycardia and tachypnea was transferred to the emergency resuscitation unit. Radiographs were delayed to confirm the diagnosis. Tube thoracostomy was scheduled urgently. The patient was placed in the left lateral position (lesion present) to prevent paradoxical respiration and for possible mechanical ventilation support. Left-sided thoracentesis was performed. Then, emergency tube thoracostomy was performed under anesthesia with positive air aspiration following local cleaning. Due to a prominent progressing paradoxical respiration in the left lung, compression with external tamponade on the rib cage was applied using braces and roller cotton bandages to support an injured limb (Figure 1). The dressing was fixed with a plaster (Figure 2). The patient was placed in the seated position and monitored for approximately 30 minutes. The vital signs, respiratory rate, and oxygen saturation values (99\% to 100\%) returned to normal.

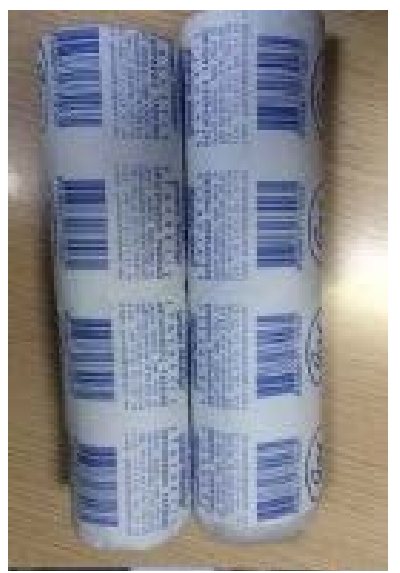

Figure 1. External tamponade materials with braces and roller cotton bandages (10-cm hard roller, $3 \mathrm{~cm}$ cylinder).

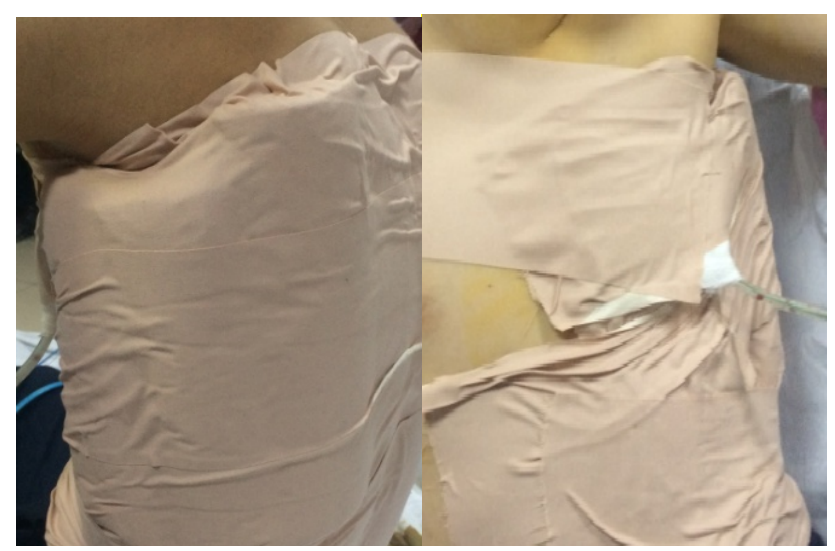

Figure 2. The dressing was fixed with a plaster and anterior view of the chest tube. 


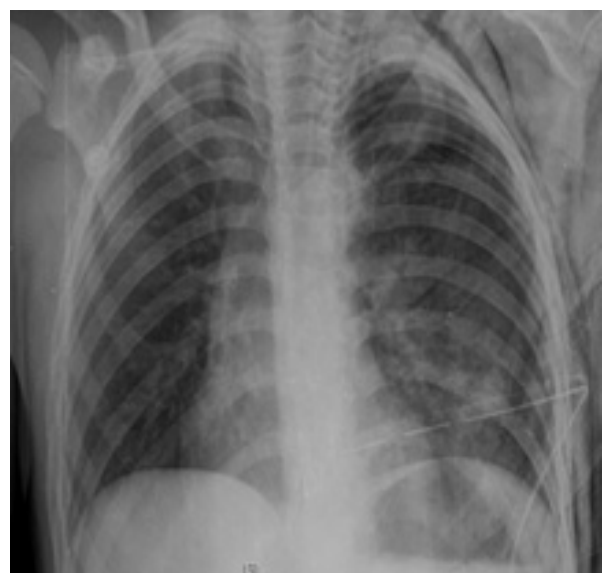

Figure 3. PAAC view following chest tube insertion .

The chest X-ray showed complete ventilation (Figure 3). The tube was re-placed and fixed with dressing. Complete blood count and biochemistry test results were normal. Arterial blood gas values were as follows: $\mathrm{pH}$ : 7.39, $\mathrm{pO}_{2}: 60 \mathrm{mmHg}$, and $\mathrm{pCO}_{2}: 39 \mathrm{mmHg}$. Abdominal ultrasonography findings showed no abdominal trauma. The patient was hospitalized with stable signs in the Department of Chest Surgery Clinic. The patient was not operated on, as the arterial blood gas value and other laboratory values were within normal ranges and respiratory movements of the chest wall returned to normal. He was discharged on the sixth postoperative day. Repeated examination and radiographs on the $15^{\text {th }}$ day after discharge showed normal results.

\section{Case Discussion}

Thoracic injuries vary with a broad spectrum of injuries from simple rib fractures to intra-thoracic organ injuries [1]. Rib fractures account for 35\% to $40 \%$ of all thoracic injuries [3] [4]. Nearly $10 \%$ to $15 \%$ of these injuries may result in flail chest [3]. The presence of more than two rib fractures indicates severe injury [1].

The underlying mechanism of flail chest is of utmost importance, as it may lead to hemodynamic instabilities. Once flail chest occurs, the anterior or lateral portion of the thorax may be affected. The injury is characterized by three consecutive lateral rib fractures at more than one site, sternal fractures, or costochondral joint separation [5]. Mediastinal flatter is the main physiopathological cause of hemodynamic instability in flail chest. It may induce torsion of the superior and inferior vena cava, irrespective of the presence of pneumothorax, characterized by paradoxical movement of a segment of the chest wall. It leads to reduced cardiac output due to decreased blood supply to the heart, and triggering hypertension, syncope, and sudden cardiac arrest [6]. Therefore, early diagnosis and management of mediastinal flatter is critical in such patients [7].

Life-threatening physiopathological changes always affect the clinical condition. In a typical flail chest, the fractured segment moves inward during inhalation and outward during exhalation, which is known as paradoxical respiration [8]. The chest wall and mediastinum stability are compromised, thereby leading to decreased cardiac venous return [9].

The diagnosis of a flail chest is based on the view of paradoxical movement of the chest wall, as well as radiographs showing rib fractures and respiratory dysfunction. In the present case, the diagnosis was made based on the presence of paradoxical respiratory movement. The severity of the respiratory dysfunction primarily depends on the size of the segment of the chest wall acting in paradoxical respiration [8] [10].

Treatment of flail chest is generally non-surgical. However, surgery is the only treatment of choice in case of the following manifestations: prominent deformity in the chest wall, inconsistent respiratory dynamics, pulmonary or diaphragmatic injury, or prolonged mechanical ventilation [1] [4].

The rib fractures can be stabilized in patients undergoing thoracotomy. Although rare, surgical reconstruction may be required for rib fractures, flail chest, or traumatic chest wall deformities. In the current case, the flail chest of the left chest wall was stabilized through emergency tube thoracostomy and external tamponade. Thanks to early intervention, neither intubation nor mechanical ventilation was required and the patient was discharged uneventfully. In general, pulmonary contusion maybe present at the injury site, which induces compromised ventilation, decreased pulmonary compliance, increased airway secretions, and altered ventilation-perfusion ratio [5]. 
Optimal treatment of flail chest includes appropriate fluid replacement, preservation of the blood volume, chest physiotherapy, effective analgesia, and nasal oxygenation to maintain a $\mathrm{pO}_{2}>80 \mathrm{mmHg}$ [3] [5] [10].

\section{Conclusion}

In conclusion, this case is presented due to its rare occurrence in the pediatric age group and a simple fall-associated flail chest. Chest stabilization is required to prevent paradoxical respiratory movement in these patients. Tamponade can be applied using practical materials in the emergency departments. In the current case, early stabilization was achieved through emergent and rapid tube thoracostomy along with external tamponade. Although emergency medicine specialists rarely encounter such cases, appropriate training should be provided to these physicians. Furthermore, a simple fall-associated flail chest as well as hemothorax and pneumothorax should be kept in mind.

\section{References}

[1] Poirier, W.J. and Vacca Jr., V.M. (2013) Flail Chest. Nursing, 43, 10-11. http://dx.doi.org/10.1097/01.NURSE.0000437477.45498.8a

[2] Inan, M., Ayvaz, S., Sut, N., Aksu, B., Basaran, U.N. and Ceylan, T. (2007) Blunt Chest Trauma in Childhood. ANZ Journal of Surgery, 77, 682-685. http://dx.doi.org/10.1111/j.1445-2197.2007.04186.x

[3] de Jong, M.B., Kokke, M.C., Hietbrink, F. and Leenen, L.P. (2014) Surgical Management of Rib Fractures: Strategies and Literature Review. Scandinavian Journal of Surgery: Official Organ for the Finnish Surgical Society and the Scandinavian Surgical Society, 103, 120-125.

[4] Dehghan, N., de Mestral, C., McKee, M.D., Schemitsch, E.H. and Nathens, A. (2014) Flail Chest İnjuries: A Review of Outcomes and Treatment Practices from the National Trauma Data Bank. The Journal of Trauma and Acute Care Surgery, 76, 462-468. http://dx.doi.org/10.1097/TA.0000000000000086

[5] Vana, P.G., Neubauer, D.C. and Luchette, F.A. (2014) Contemporary Management of Flail Chest. The American Surgeon, 80, 527-535.

[6] Piastra, M., De Luca, D., Zorzi, G., Ruggiero, A., Antonelli, M., Conti, G., et al. (2008) Noninvasive Ventilation in Large Postoperative Flail Chest. Pediatric Blood \& Cancer, 51, 831-833. http://dx.doi.org/10.1002/pbc.21749

[7] Taylor, B.C. and French, B.G. (2013) Successful Treatment of a Recalcitrant Pleural Effusion with Rib Fracture Fixation. HSS Journal: The Musculoskeletal Journal of Hospital for Special Surgery, 9, 96-99. http://dx.doi.org/10.1007/s11420-012-9282-z

[8] Ismail, M.F. and Al-Refaie, R.I. (2012) Chest Trauma in Children, Single Center Experience. Archivos de Bronconeumologia, 48, 362-366. http://dx.doi.org/10.1016/j.arbr.2012.07.007

[9] Lozano-Corona, R., Loyola-Garcia, U., Partida, I.C. and Rodriguez-Ortega, F. (2013) Successful Treatment of Flail Chest with Chondrosternal Disruption and Traumatic Parasternal Lung Hernia with Titanium Rib Bridges. BMJ Case Reports.

[10] Messing, J.A., Gall, V. and Sarani, B. (2014) Successful Management of Severe Flail Chest via Early Operative Intervention. Journal of Trauma Nursing: The Official Journal of the Society of Trauma Nurses, 21, 83-85.

http://dx.doi.org/10.1097/JTN.0000000000000039 
Scientific Research Publishing (SCIRP) is one of the largest Open Access journal publishers. It is currently publishing more than 200 open access, online, peer-reviewed journals covering a wide range of academic disciplines. SCIRP serves the worldwide academic communities and contributes to the progress and application of science with its publication.

Other selected journals from SCIRP are listed as below. Submit your manuscript to us via either submit@scirp.org or Online Submission Portal.
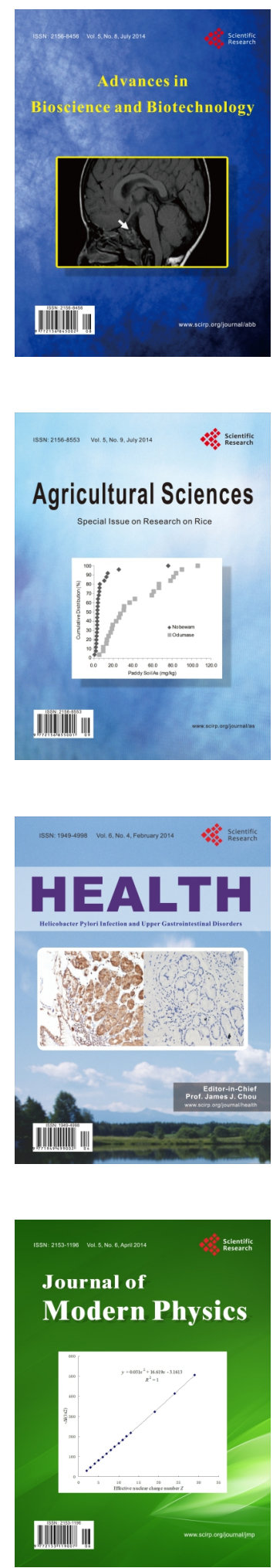
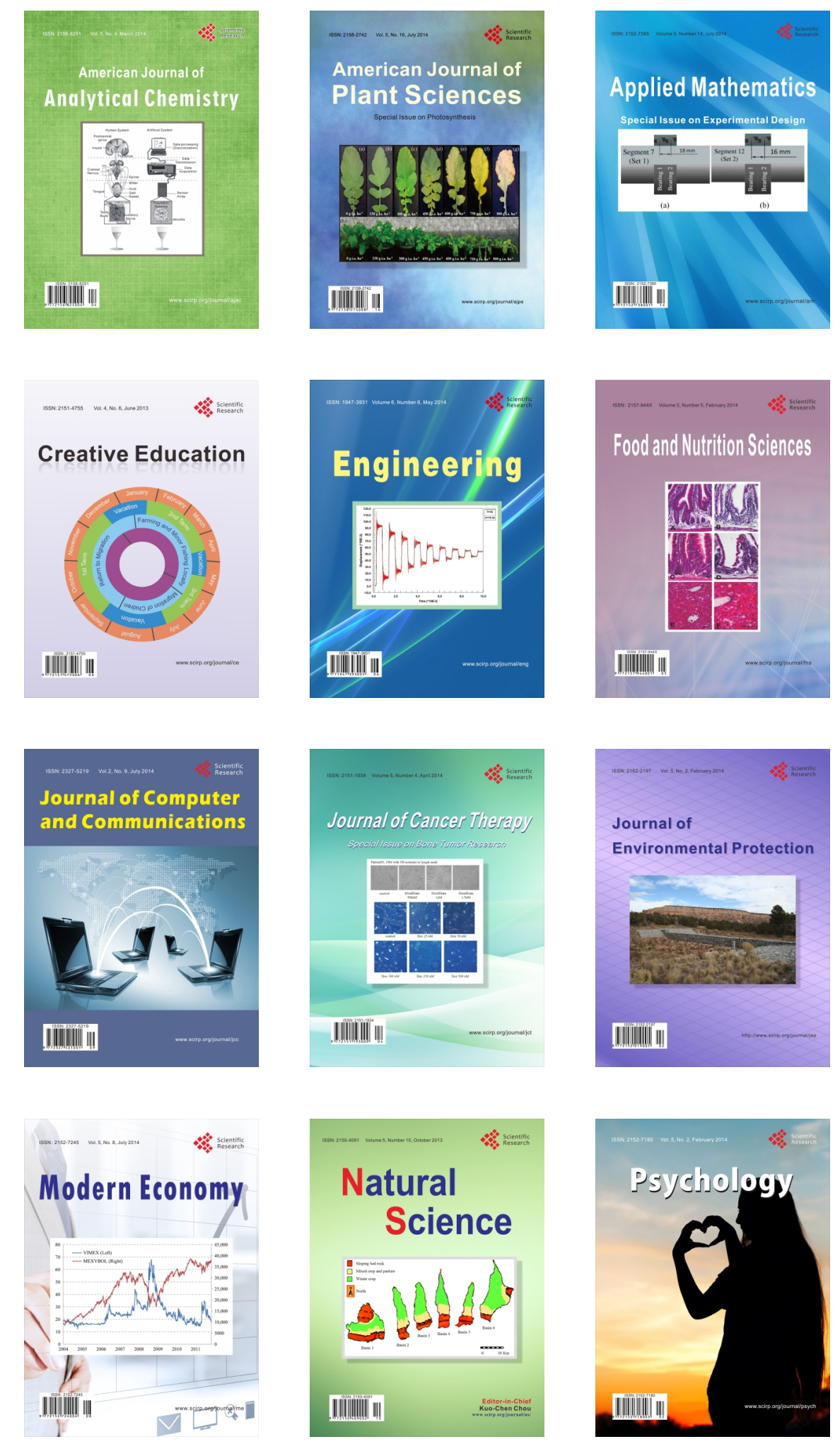